tables are comprehensive, careful and rather out of date.

The Summary Tables include details of population, age and marital condition, birthplace and nationality, fertility, migration, occupation, household composition, and age of leaving school. The population of Great Britain in 1961 was $51.35 \mathrm{~m}$, made up of $24.7 \mathrm{~m}$ males and $26.6 \mathrm{~m}$ females, which represents a doubling of the population since 1870. Some of the tables are based on a complete return, while others are based on a 10 per cent sample. For these, sampling errors are defined. Even a 100 per cent return is no guarantee of accuracy, however, as the tables show. In 1961 for the first time a post-enumeration survey was carried out to check the information collected at the census; this shows that in some cases the information given in the census returns was inaccurate. The reasons for the inaccuracies are not given, but presumably they are caused either by ambiguities in the census form, or by simple reluctance of the people filling in the form to admit the truth. The number of women in employment, for instance, was understated, as was the number of households without a water closet. $1.08 \mathrm{~m}$ households without a water closet seems a remarkably high figure, but is likely to be an underestimate; the postenumeration survey showed that the figure might be nearer $1.5 \mathrm{~m}$. Facts like these show the great interest of the census returns; they would be easier to read, though, if they had better indexes.

\section{Transports of Despair}

THE British Ministry of Transport must be feeling baffled by the sharp rise in road casualties over the Christmas holiday. Just two days before the holiday began, the Ministry issued figures for September 1966 which show that for the fourth successive month fewer people were killed and injured on the roads. In September there were 31,911 casualties, a figure which hardly gives cause for dancing in the streets, but which is nevertheless a reduction of 7 per cent compared with September 1965 despite a 7 per cent increase in traffic density since then. By contrast, the three days of the Christmas holiday showed an increase in casualties from 2,853 to 3,335 (17.5 per cent), and of deaths from 55 to 80 .

Both sets of figures are worth closer examination. Over the Christmas period the number of injuries was actually produced by fewer accidents than last yearindeed, the Ministry of Transport figures show 5 per cent fewer accidents for Christmas 1966. A number of inferences can be drawn from this, but the most obvious way in which the number of people involved in each accident is increased is by increasing the number in each car. In response to the appeal not to drink and drive, people may well have left their cars at home and taken lifts with friends, a course of action long recommended by the ministry and the motoring organizations. If this interpretation is correct, minor injuries should show a much steeper rise than major injuries, since the back seats of cars are much safer than the front. In fact, this is exactly what did happen; slight injuries increased by 22 per cent, serious injuries by only 2.5 per cent. Of course, it is risky to interpret the figures without more detailed information; interpretation is really the job of the ministry.

The ministry attributes the improvement in the
September figures to the decline of two wheeled vehicles. The mileage covered by bicycles has declined for some years, and since 1960 the mileage covered by mopeds, scooters and motor bicycles has also declined. For every mile travelled, users of two wheeled vehicles suffered ten times as many fatal and serious injuries as drivers of cars, so the switch to safer vehicles has brought about a reduction in casualties, although the casualty rates for individual classes of vehicle have in many cases increased. To be sure, this conclusion will confound no one but the scooter manufacturers, but people are entitled to ass the ministry one plaintive question. Why, if two wheeled vehicles are so dangerous, does the ministry encourage their sale by letting young people ride them for a year before they are considered old enough to drive a car ?

\section{Supersonic Contract}

THE complex problem of deciding which of the two claimants to the U.S. Supersonic Transport contract has produced the better design has been settled to the satisfaction of the Federal Aviation agency, President Johnson and the Boeing Aircraft Corporation. The agency has selected the Boeing swing-wing design in preference to the Lockheed double-delta, and engines by the General Electric Company rather than Pratt and Whitney. The decision came as no great surprise, for the airlines consulted by the agency were reported to prefer the Boeing design.

The supersonic transport battle now resolves into one between the Boeing design, with a speed of 1,800 m.p.h. and room for up to 350 passengers, and the Anglo-French Concord, which will carry 136 passengers at 1,450 m.p.h. In the background, competing for prestige if not economic gain, is the Russian Tul44, which has a specification remarkably similar to that of Concord, carrying 126 passengers at 1,500 m.p.h. The Boeing design, which will cost $\$ 35 \mathrm{~m}$ against the Concord price of $\$ 16$, is clearly the most ambitious of the three, but is three years behind the other two; both the Russian and the Anglo-French designs are to make their first flights in 1968, while the Boeing design is still at the mock-up stage, and earlier this year underwent radical design alterations.

The striking feature of the Boeing design is the use of wings which swing from a position at right angles to the fuselage at take-off through an intermediate position while climbing at subsonic speed and finally link up with the tail to form a delta-wing for high altitude cruising. Boeing claims that this design concept is well tested and proved, although some airlines are reported to have expressed alarm about it. It undoubtedly improves efficiency, particularly in take-off and landing, but the engineering which it makes necessary adds weight and offsets some of this advan. tage. In fact the take-off and landing speeds and distances required by the two rival American designs are remarkably similar; where the Boeing design would presumably gain would be in using the engines at lower power when circling and landing, a reduction both in cost and in annoyance by noise.

The problem of noise may well turn out to be more significant than is usually realized. It is already being seriously suggested that certification of aircraft should include permitted noise levels, and while this is unlikely to happen next week, it could be a reality in five 